\title{
Enhanced recovery after surgery (ERAS) effectief bij robotgeassisteerde radicale cystectomie (RARC); standaardisatie gewenst
}

\author{
Coen Holzhauer $^{1}$ (D) - Philip C. Weijerman ${ }^{1}$ Geert A. H. J. Smits ${ }^{1}$ Carl J. Wijburg ${ }^{1}$
}

Published online: 4 October 2016

(C) The Author(s) 2016. This article is available at SpringerLink with Open Access.

Samenvatting Het doel van het ERAS-protocol is het postoperatieve herstel te optimaliseren. Om te inventariseren welke invulling landelijk gegeven wordt aan dit protocol, hebben wij een enquête gehouden onder Nederlandse urologen. Hieruit bleek dat er nog veel verschillen bestaan tussen de ziekenhuizen. Om het effect van ERAS te onderzoeken, hebben wij een onderzoek gedaan in onze eigen kliniek.

In deze studie hebben wij de resultaten vergeleken van de robotgeassisteerde radicale cystectomie met intracorporele reconstructie (RARC-IC) voor en na de introductie van het ERAS-protocol. 37 patiënten zijn geopereerd in de periode voor introductie van het protocol en 71 erna. Preoperatief waren er geen verschillen tussen beide groepen. De OKtijd verminderde significant en de gemiddelde opnameduur daalde van 14 naar acht dagen. Het aantal complicaties nam niet toe. De afgenomen OK-tijd is te verklaren vanuit het doorlopen van de RARC-leercurve. Verder onderzoek moet aantonen hoe het ideale ERAS-protocol eruit moet zien en wat de meerwaarde is van een dergelijk protocol.

Trefwoorden robot - cystectomie - minimaal invasief . protocol $\cdot$ perioperatief management $\cdot$ enhanced recovery after surgery (ERAS)

\footnotetext{
dr. Coen Holzhauer

coenholzhauer@gmail.com

1 afdeling Urologie, Rijnstate, Arnhem, Nederland
}

\section{Enhanced recovery after surgery (ERAS) effective for robot-assisted radical cystectomy (RARC); standardization wanted}

\begin{abstract}
ERAS is designed for optimization of the perioperative process. We conducted a survey of implementation of ERAS in Dutch hospitals. Many differences were found. We also examined the results of the RARC-IC before and after introduction of the ERAS-protocol in our own hospital. 37 patients were treated before introduction of ERAS, 71 were treated after introduction. There were no differences between both groups preoperative. The OR-time significantly decreased and length-of-stay decreased from 14 to eight days. Complications were similar. The decrease in OR-time is due to the learning curve of the RARC-IC. Further research has to be done to find the ideal ERAS protocol.
\end{abstract}

Keywords robot $\cdot$ cystectomy $\cdot$ minimal invasive $\cdot$ perioperative management $\cdot$ enhanced recovery after surgery (ERAS)

\section{Introductie}

Om de complicaties binnen de colorectale chirurgie te verminderen, bestaat sinds begin deze eeuw het ERAS-protocol (enhanced recovery after surgery). Een ERAS-protocol is een kwaliteitsprogramma rondom een operatie, waarin alle factoren die een positieve invloed hebben op herstel zijn samengebracht. Dit protocol is ontwikkeld om het pre-, per- en postoperatieve traject zo vlekkeloos mogelijk te laten verlopen. Zo blijkt het herstel na de operatie versneld te kunnen worden door: 
- een zo klein mogelijke incisie,

- een optimale pijnbestrijding met zo min mogelijk opiaten om negatieve effecten op maag- en darmfunctie te voorkomen,

- snel herstarten van een normaal dieet om gewichtsverlies (en daarmee verlies van spiermassa en spierkracht) te voorkomen,

- snel mobiliseren om verlies van spierkracht te beperken.

In een meta-analyse van de toepassing van ERAS bij colorectale chirurgie werd aangetoond dat er significant minder complicaties optraden (reductie van $50 \%$ ) en dat er een significante kortere opnameduur (reductie van 2,5 dag) was na het introduceren van ERAS [1].

De radicale cystectomie is een ingreep met een hoge morbiditeit, waarbij meer dan $10 \%$ van de patiënten postoperatief een Clavien graad 3-complicatie of hoger heeft [2]. Aangezien darmchirurgie onderdeel uitmaakt van een radicale cystectomie, bestaat de mogelijkheid dat ook bij deze operatie gebruik van een ERAS-protocol de kans op complicaties vermindert en de snelheid van het herstel verbetert. Er is echter nog weinig bekend over de toepassing van een ERAS-protocol binnen de urologie.

Wij hebben met een vragenlijst de toepassing van een ERAS-protocol bij de cystectomie in de Nederlandse ziekenhuizen geïnventariseerd. Daarnaast hebben wij het effect van de introductie van een ERAS-protocol bij de robotgeassisteerde radicale cystectomie met intracorporele reconstructie (RARC-IC) in onze kliniek geanalyseerd.

\section{Materiaal en methoden}

Van de 45 klinieken die wij hadden aangeschreven met de vraag of zij deel wilden nemen aan onze online enquête (Survey Monkey ${ }^{\circledR}$ ), vulde $38 \%$ de enquête in. De enquête bestond uit 16 meerkeuzevragen over de invulling van het ERAS-protocol binnen het eigen ziekenhuis.

Het effect van de invoering van het ERAS-protocol op het postoperatieve beloop werd ook onderzocht in onze eigen kliniek. Het betrof een retrospectief dataonderzoek waarbij is geput uit onze prospectieve RARC-database. Patiënten werden geopereerd tussen november 2010 en april 2015. Sinds de introductie van RARC-IC in 2010 werden 108 patiënten geopereerd. Van deze patiënten werden er 37 geopereerd vóór introductie van het ERAS-protocol (januari 2013) en 71 patiënten erna. Wij verzamelden demografische en perioperatieve gegevens over beide groepen. Complicaties die gedurende de eerste 30 dagen postoperatief waren opgetreden en complicaties die na 90 dagen waren opgetreden, werden gescoord volgens Clavien-Dindo [3]. Tevens werd de totale opnameduur in dagen geïnventariseerd, scoorden wij het voorkomen van een ileus, de duur tot aan defecatie en hoelang totale parenterale voeding (TPV) was gebruikt.

De uitkomsten van de groep vóór en van de groep na introductie van het ERAS-protocol werden met elkaar vergeleken. Hierbij werd gebruikgemaakt van SPSS Statistics v20. Data van continue variabelen werden gepresenteerd als gemiddelden en van discrete variabelen als proporties. Met een Pearson-chikwadraattoets zijn non-parametrische data vergeleken, een ongepaarde T-toets werd gebruikt voor het vergelijken van parametrische variabelen. Een $p$-waarde $<0,05$ werd als statistisch significant beschouwd.

\section{Resultaten}

\section{Resultaten van de enquête}

De aanpak bleek op veel punten per ziekenhuis sterk te verschillen. Zo was er grote variatie in de antwoorden op vragen over: de verwijzingen naar een diëtist preoperatief; het geven van drinkvoeding preoperatief; wel of geen darmvoorbereiding; antibiotische profylaxe; operatietechniek; gebruik van een epiduraalkatheter; verwijderen van de maaghevel; maatregelen om een postoperatieve ileus te voorkomen en welk dieet postoperatief wordt aangehouden. Zie voor alle resultaten tab. 1 .

\section{Resultaten van de invoering van het ERAS-protocol in de eigen kliniek}

De mediane leeftijd tussen beide groepen verschilde niet significant $(p=0,09)$. Ook de preoperatieve ASA-scores verschilden niet significant $(p=0,37)$. Er was geen verschil tussen de oncologische stadiëring $(p=0,22)$ van beide groepen. De pre- en peroperatieve resultaten staan in tab. 2 .

De OK-tijd (skin-to-skin) in de groep vóór introductie van het ERAS-protocol was 365,7 minuten; dit was significant langer dan na introductie van het protocol $(p<0,01)$ (306,3 minuten). Het gemiddelde bloedverlies verschilde niet significant: $247 \mathrm{ml}$ vóór versus $239 \mathrm{ml}$ na introductie van het protocol.

De mediane opnameduur, die voor introductie 14 dagen bedroeg, was na introductie significant teruggelopen tot acht dagen $(p<0,01)$. Het aantal complicaties (30 en 90 dagen postoperatief) veranderde niet na introductie van het protocol. Vóór introductie van het protocol deed zich bij $18,9 \%$ van de patiënten een ileus voor, na introductie trad een ileus op bij $16,9 \%(p=0,46)$ van de patiënten. Het protocol had wel effect op de mediane tijd tot de eerste defecatie: die bedroeg vijf dagen toen het protocol nog niet werd gebruikt en vier dagen na introductie ervan $(p<$ $0,01)$. Het gebruik van totale parenterale voeding (TPV) nam ook af na introductie van het protocol: het mediane 
Tabel 1 Uitkomsten van de enquête.

\begin{tabular}{|c|c|}
\hline vraag & uitkomst (\%) \\
\hline $\begin{array}{l}\text { preoperatieve counseling oncologie- } \\
\text { verpleegkundige }\end{array}$ & $\begin{array}{l}\text { ja }(82,4) \\
\text { soms }(5,9) \\
\text { nee }(11,7)\end{array}$ \\
\hline preoperatieve screening diëtiste & $\begin{array}{l}\text { ja }(5,9) \\
\text { soms }(70,6) \\
\text { nee }(23,5)\end{array}$ \\
\hline $\begin{array}{l}\text { preoperatieve counseling stomaver- } \\
\text { pleegkundige }\end{array}$ & $\begin{array}{l}\text { ja }(100) \\
\text { soms }(0) \\
\text { nee }(0)\end{array}$ \\
\hline $\begin{array}{l}\text { preoperatief foldermateriaal over de } \\
\text { operatie en opname }\end{array}$ & $\begin{array}{l}\text { ja }(100) \\
\text { nee }(0)\end{array}$ \\
\hline nuchter voorafgaand aan de operatie & $\begin{array}{l}6 \text { uur volledig nuchter }(31,2) \\
6 \text { uur volledig en } 2 \text { uur hel- } \\
\text { der vloeibaar }(56,3) \\
\text { anders }(12,5)\end{array}$ \\
\hline $\begin{array}{l}\text { preoperatief drinkvoeding met hoge } \\
\text { calorische waarde }\end{array}$ & $\begin{array}{l}\text { ja }(43,7) \\
\text { nee }(56,3)\end{array}$ \\
\hline type darmvoorbereiding & $\begin{array}{l}\text { klean-prep }(6,3) \\
\text { hoogopgaand klysma }(6,2) \\
\text { gewoon klysma }(37,5) \\
\text { geen }(50,0)\end{array}$ \\
\hline antibioticaprofylaxe & $\begin{array}{l}\text { cefazoline }+ \text { metronidazol } \\
(43,7) \\
\text { cefuroxim }+ \text { metronidazol } \\
(18,7) \\
\text { anders }(37,5)\end{array}$ \\
\hline operatietechniek & $\begin{array}{l}\text { ORC }(68,7) \\
\text { RARC-IC }(25,0) \\
\text { RARC-EC }(6,3) \\
\text { LRC }(0)\end{array}$ \\
\hline plaatsen epiduraalkatheter & $\begin{array}{l}\text { ja }(75) \\
\text { soms }(6,3) \\
\text { nee }(18,7)\end{array}$ \\
\hline plaatsen maaghevel & $\begin{array}{l}\text { ja }(87,5) \\
\text { nee }(12,5)\end{array}$ \\
\hline verwijderen maaghevel? & $\begin{array}{l}\text { direct postoperatief }(43,7) \\
1 \text { dag postoperatief }(25) \\
\text { op geleide van de kliniek } \\
(31,3)\end{array}$ \\
\hline voorkomen postoperatieve ileus & $\begin{array}{l}\text { kauwgom }(37,5) \\
\text { erytromycine }(0) \\
\text { magnesiumkauwtabletten } \\
(18,7) \\
\text { movicolon }(18,8) \\
\text { anders }(25,0)\end{array}$ \\
\hline anti-emetica postoperatief & $\begin{array}{l}\text { zo nodig }(50) \\
\text { standaard }(43,8) \\
\text { nee }(6,2)\end{array}$ \\
\hline dieet postoperatief & $\begin{array}{l}\text { wensdieet }(50) \\
\text { vloeibaar tot buik op gang } \\
(18,7) \\
\text { vloeibaar } 2 \text { dagen en nadien } \\
\text { naar wens }(6,3) \\
\text { anders }(25)\end{array}$ \\
\hline $\begin{array}{l}\text { fysiotherapie standaard betrokken } \\
\text { postoperatief }\end{array}$ & $\begin{array}{l}\text { ja }(56,3) \\
\text { op indicatie }(43,7)\end{array}$ \\
\hline
\end{tabular}

$E C$ extracorporele procedure, $I C$ intracorporele procedure, $L R C$ laparoscopische radicale cystectomie, ORC open radicale cystectomie, $R A R C$ robotgeassisteerde radicale cystectomie
Tabel 2 Pre- en peroperatieve resultaten.

\begin{tabular}{|c|c|c|c|}
\hline & $\begin{array}{l}\text { zonder } \\
\text { ERAS }\end{array}$ & met ERAS & $p$ \\
\hline aantal patiënten & 37 & 71 & \\
\hline man:vrouw & $31: 6$ & $59: 12$ & 0,58 \\
\hline $\begin{array}{l}\text { mediane leeftijd } \\
(95 \%-B I)\end{array}$ & $\begin{array}{l}67,2 \\
(49,8-83,0)\end{array}$ & $\begin{array}{l}68,7 \\
(55,2-82,1)\end{array}$ & 0,09 \\
\hline ASA-score (\%) & & & 0,37 \\
\hline $\begin{array}{l}1 \\
2 \\
3\end{array}$ & $\begin{array}{l}12(32,4) \\
20(54,1) \\
5(13,5)\end{array}$ & $\begin{array}{l}17(23,9) \\
37(52,1) \\
17(23,9)\end{array}$ & \\
\hline body-mass index & 25,2 & 26,5 & 0,10 \\
\hline $\begin{array}{l}\text { preoperatieve stadië- } \\
\text { ring }(\%)\end{array}$ & & & 0,22 \\
\hline $\mathrm{Ta}$ & $0(0,0)$ & $8(11,3)$ & \\
\hline $\mathrm{T} 1$ & $4(10,8)$ & $11(15,5)$ & \\
\hline $\mathrm{T} 2$ & $26(70,3)$ & $45(63,4)$ & \\
\hline $\mathrm{T} 3$ & $3(8,1)$ & $2(2,8)$ & \\
\hline $\mathrm{T} 4$ & $3(8,1)$ & $3(4,2)$ & \\
\hline Tis & $1(2,7)$ & $2(2,8)$ & \\
\hline $\begin{array}{l}\text { neoadjuvante chemo- } \\
\text { therapie }\end{array}$ & & & 0,14 \\
\hline nee & $37(100,0)$ & $67(94,4)$ & \\
\hline ja & $0(0,0)$ & $4(5,6)$ & \\
\hline neoblaas:Bricker & $2: 35$ & $2: 68$ & 0,62 \\
\hline $\begin{array}{l}\text { bloedverlies in } \mathrm{ml} \\
\text { (SD) }\end{array}$ & $\begin{array}{l}247,3 \\
( \pm 278,6)\end{array}$ & $\begin{array}{l}239,1 \\
( \pm 229)\end{array}$ & 0,88 \\
\hline OK-tijd in min. (SD) & $\begin{array}{l}365,7 \\
( \pm 66,8)\end{array}$ & $\begin{array}{l}306,3 \\
( \pm 71)\end{array}$ & $<0,01$ \\
\hline
\end{tabular}

aantal dagen daalde van zes naar nul $(p<0,01)$. Als wij de patiënten met een ileus buiten beschouwing laten, zien we ook een verschil tussen de tijd tot defecatie: 4,5 versus 4 dagen $(p<0,01)$ en ook bij het aantal dagen TPV, 4,5 versus 0 dagen $(p<0,01)$. Alle postoperatieve resultaten staan in tab. 3 .

\section{Discussie}

Waar het positieve effect van het ERAS-protocol binnen de colorectale chirurgie duidelijk is, is de meerwaarde van het protocol bij de radicale cystectomie nog niet onomstotelijk aangetoond. Als bewezen kan worden dat een ERAS-protocol een positieve invloed heeft op de radicale cystectomie, zal daarna naar de juiste invulling van zo'n protocol meer onderzoek gedaan moeten worden.

Onze enquête onder Nederlandse urologen laat zien dat er over veel onderwerpen geen consensus is. Een hogere respons dan $38 \%$ zal mogelijk een nog grotere diversiteit laten zien dan nu naar voren komt. Standaardisatie lijkt dan ook gewenst, zeker om in de toekomst onderzoek te kunnen doen met grotere patiëntenaantallen en met multicentrisch onderzoek. De diversiteit in de invulling en uitvoering van het ERAS-protocol bij de radicale cystectomie werd eerder 
Tabel 3 Postoperatieve resultaten voor en na invoering van het ERAS-protocol.

\begin{tabular}{|c|c|c|c|}
\hline & zonder ERAS & met ERAS & $p$ \\
\hline $\begin{array}{l}\text { mediane opnameduur in } \\
\text { dagen }(95 \% \text {-BI })\end{array}$ & $\begin{array}{l}14 \\
(7,8-39,10)\end{array}$ & $\begin{array}{l}8 \\
(5,6-40,6)\end{array}$ & $<0,01$ \\
\hline aantal ileus $(\%)$ & $7(18,9 \%)$ & $\begin{array}{l}12 \\
(16,9 \%)\end{array}$ & 0,46 \\
\hline $\begin{array}{l}\text { mediane tijd tot defeca- } \\
\text { tie in dagen }(95 \%-\mathrm{BI})\end{array}$ & $5(2,9-14,1)$ & $4(2-8)$ & $<0,01$ \\
\hline $\begin{array}{l}\text { mediane duur van TPV } \\
\text { in dagen }(95 \% \mathrm{CI})\end{array}$ & $6(0-13,1)$ & $0(0-10)$ & $<0,01$ \\
\hline \multicolumn{4}{|l|}{$\begin{array}{l}\text { Clavien-score na } \\
<30 \text { dagen }(\%)\end{array}$} \\
\hline $\begin{array}{l}\text { geen } \\
\text { laag }^{\text {a }} \\
\text { hoog }^{b}\end{array}$ & $\begin{array}{l}14(37,8) \\
17(45,9) \\
6(16,2)\end{array}$ & $\begin{array}{l}34(47,9) \\
29(41,4) \\
7(10,0)\end{array}$ & 0,47 \\
\hline \multicolumn{4}{|l|}{$\begin{array}{l}\text { Clavien-score na } \\
\text { 31-90 dagen }(\%)\end{array}$} \\
\hline $\begin{array}{l}\text { geen } \\
\text { laagg }^{\text {a }} \\
\text { hoog }^{b}\end{array}$ & $\begin{array}{l}32(86,5) \\
1(2,7) \\
4(10,8)\end{array}$ & $\begin{array}{l}59(83,1) \\
5(7,0) \\
7(9,9)\end{array}$ & 0,64 \\
\hline
\end{tabular}

$T P V$ totale parenterale voeding

${ }^{\mathrm{a}} \mathrm{Laag}=1$ en 2

${ }^{\mathrm{b}} \mathrm{Hoog}=3$ en 4

aangetoond in een vergelijkbare studie van Kukreja et al. onder Engelse urologen [4].

Het ERAS-protocol dat tijdens onze studie is gebruikt, is grotendeels gebaseerd op het protocol van de colorectale chirurgie. Bij ons in de kliniek hebben wij het protocol aangepast door gedurende de eerste drie dagen postoperatief een vloeibaar dieet aan te bieden. Deze aanpassing werd doorgevoerd op grond van het vermoeden, dat werd bevestigd in de klinische praktijk, dat na een RARC, in vergelijking met colonchirurgie, een grotere kans bestaat op een postoperatieve ileus; mogelijk ten gevolge van een anastomose van de dunne darm in plaats van een anastomose van de dikke darm, in combinatie met het effect van intraperitoneale urine. Om die reden is de veronderstelling dat orale belasting in een RARC-georiënteerd protocol niet precies gelijk kan zijn aan het opstarten van de orale belasting in een op colorectale chirurgie georiënteerd protocol. Deze veronderstelling zal in de toekomst moeten worden getoetst.

Een toekomstig gespecificeerd ERAS-protocol voor cystectomie zou eruit kunnen zien zoals het protocol dat is opgesteld voor de RACE-studie (www.racestudie.nl). Er is nog geen vergelijkend onderzoek gedaan naar de verschillende protocollen voor open radicale cystectomie (ORC) en RARC. Het is aannemelijk dat er in de toekomst verschillende protocollen zullen komen voor de open en de minimaal invasieve operatietechnieken. In de enquête wordt bij twee derde van de respondenten een open procedure toegepast, de rest past de robotgeassisteerde techniek toe.
Het ERAS-protocol van de RACE-studie is opgesteld op basis van de op dit moment beschikbare wetenschappelijke basis, zoals benoemd in het artikel van de ERAS Society [5], en aangepast op grond van de ervaringen in onze eigen kliniek. Het enige verschil met het door ons gebruikte protocol ten tijde van studie in onze eigen kliniek, is dat gebruik van een thoracale epiduraalkatheter is gestandaardiseerd, wat daarvoor optioneel was. In de ERAS Society Guidelines staan 21 aspecten van het ERAS-protocol, inclusief de wetenschappelijke onderbouwing daarvan, indien aanwezig vanuit urologisch onderzoek en, indien bewijs ontbreekt vanuit de urologie, vanuit de colorectale chirurgie (zie tab. 4; [5]). Verderop in de discussie zullen deze 21 aspecten worden besproken.

Om de effectiviteit van het ERAS-protocol te onderzoeken, hebben wij de data in onze RARC-database geanalyseerd. Uit onze analyse bleek dat de opnameduur significant kan worden verkort door het toepassen van het ERAS-protocol. Deze kortere opnameduur gaat niet gepaard met een toename in het aantal complicaties. De kortere operatietijd in de ERAS-groep kan invloed hebben gehad op het aantal complicaties en de opnameduur. De kortere operatietijd kan verklaard worden met de leercurve die in deze serie zit. Voor zover bekend, varieert de leercurve voor RARC van 16 tot 30 ingrepen [6, 7], maar waarschijnlijk is de leercurve langer.

Voor introductie van het ERAS-protocol werd de maaghevel standaard postoperatief ingehouden, tot de defecatie op gang was gekomen. Na introductie van het protocol werd de maaghevel standaard postoperatief verwijderd. Dit heeft niet geleid tot het frequenter voorkomen van een ileus. Bij $16,9 \%$ van de patiënten werd alsnog een neus-maagsonde geplaatst. Het ERAS-protocol schrijft voor dat alle patiënten vanaf zes uur na operatie op de rand van het bed mogen zitten en vanaf de eerste postoperatieve dag starten met mobiliseren. In de praktijk is op de rand van het bed zitten de avond na de operatie niet altijd haalbaar, maar in de stoel zitten vanaf de eerste dag postoperatief in meer dan $90 \%$ van de gevallen wel.

De duur tot de eerste defecatie was duidelijk korter in de groep waarin het ERAS-protocol werd gevolgd en ook werd TPV in deze groep korter gebruikt. Een ileus komt in beide groepen even vaak voor, maar ERAS lijkt wel een positief effect te hebben op de tijd tot eerste defecatie en het gebruik van TPV.

Karl et al. [8] voerden een prospectief gerandomiseerde studie uit naar het effect op de kwaliteit van leven (QoL) van het ERAS-protocol bij de radicale cystectomie. De QoL nam in de groep met ERAS toe gedurende de opname; in de groep zonder ERAS veranderde de QoL niet. In de ERASgroep werden ook minder DVT's gezien, kwamen minder wondinfecties voor, trad minder vaak koorts op en werden minder pijnstillers gebruikt. Patiënten met ERAS verbleven 
Tabel 4 ERAS-protcol per item met beschrijving en onderbouwing vanuit urologie of colorectale chirurgie en aanbeveling vanuit de werkgroep [5].

\begin{tabular}{|c|c|c|c|}
\hline ERAS-item & beschrijving & bewijs cystectomie/colorectaal & mate van aanbeveling \\
\hline $\begin{array}{l}\text { preoperatieve coun- } \\
\text { seling }\end{array}$ & $\begin{array}{l}\text { patiënten moeten voldoende preoperatieve counseling } \\
\text { krijgen; mondeling en op papier uitleg over opname, } \\
\text { uitleg over stoma }\end{array}$ & NA/laag & sterk \\
\hline \multirow{6}{*}{$\begin{array}{l}\text { preoperatieve } \\
\text { optimalisatie van de } \\
\text { conditie }\end{array}$} & preoperatief optimaliseren van de conditie & NA/matig & sterk \\
\hline & zorgen voor goede voedingstoestand preoperatief & NA/hoog & \\
\hline & correctie van de anemie & NA/matig & \\
\hline & voedingsondersteuning & $\mathrm{NA} / \mathrm{matig}$ & \\
\hline & stoppen met roken en alcohol 4 weken preoperatief & NA/laag & \\
\hline & aanmoedigen voldoende te bewegen & NA/laag & \\
\hline $\begin{array}{l}\text { orale darmvoorbe- } \\
\text { reiding }\end{array}$ & orale darmvoorbereiding niet nodig & matig/hoog & sterk \\
\hline $\begin{array}{l}\text { preoperatief calo- } \\
\text { rierijke drank }\end{array}$ & $\begin{array}{l}\text { preoperatief drinkvoeding met hoge calorische waarde } \\
\text { tot } 2 \text { uur preoperatief }\end{array}$ & NA/laag & sterk \\
\hline $\begin{array}{l}\text { preoperatief beleid } \\
\text { rondom nuchter } \\
\text { zijn }\end{array}$ & $\begin{array}{l}\text { tot } 2 \text { uur preoperatief helder vloeibaar, vast voedsel tot } \\
6 \text { uur preoperatief }\end{array}$ & NA/matig & sterk \\
\hline $\begin{array}{l}\text { preanesthesie- } \\
\text { medicatie }\end{array}$ & vermijden van langwerkende benzodiazepines & NA/matig & sterk \\
\hline tromboseprofylaxe & $\begin{array}{l}\text { dragen van compressiekousen tijdens de opname en } \\
\text { profylaxe van LMWH } 4 \text { weken postoperatief }\end{array}$ & NA/hoog & sterk \\
\hline epiduraal & epiduraal te verkiezen boven opiaten, gedurende 72 uur & NA/hoog & sterk \\
\hline $\begin{array}{l}\text { minimaal invasieve } \\
\text { techniek }\end{array}$ & $\begin{array}{l}\text { in trialsetting } \\
\text { nog geen oncologische langetermijnresultaten }\end{array}$ & laag/matig & sterk \\
\hline \multirow[t]{2}{*}{$\begin{array}{l}\text { drainage middels } \\
\text { drain }\end{array}$} & $\begin{array}{l}\text { peri-anastomose drain en/of drain Douglas kunnen ach- } \\
\text { terwege gelaten worden }\end{array}$ & NA/laag & zwak \\
\hline & bij cystectomie ook risico op urinelekkage & NA/laag & \\
\hline \multirow{2}{*}{$\begin{array}{l}\text { antibioticaprofylaxe } \\
\text { en huiddesinfectie }\end{array}$} & antibiotische profylaxe 1 uur voor incisie (cefalosporine) & NA/hoog & sterk \\
\hline & huiddesinfectie verkleint kans op wondinfectie & $\mathrm{NA} / \mathrm{matig}$ & \\
\hline $\begin{array}{l}\text { standaard anesthe- } \\
\text { sieprotocol }\end{array}$ & $\begin{array}{l}\text { handhaven van adequaat vochtbeleid, voldoende oxyge- } \\
\text { natie, voldoende verslapping en afdoende pijnstilling }\end{array}$ & NA/matig & sterk \\
\hline $\begin{array}{l}\text { perioperatief vocht- } \\
\text { beleid }\end{array}$ & $\begin{array}{l}\text { goal-directed fluid therapy middels monitoring cardiac } \\
\text { output en gebruik van vasopressoren }\end{array}$ & laag/hoog & sterk \\
\hline $\begin{array}{l}\text { perioperatief voor- } \\
\text { komen van hypo- } \\
\text { thermie }\end{array}$ & $\begin{array}{l}\text { normale lichaamstemperatuur handhaven per- en post- } \\
\text { operatief }\end{array}$ & NA/hoog & sterk \\
\hline neus-maagsonde & $\begin{array}{l}\text { postoperatief geen indicatie voor een neus-maagsonde } \\
\text { advies is direct postoperatief verwijderen }\end{array}$ & laag/hoog & sterk \\
\hline \multirow[t]{2}{*}{ urinedrainage } & gebruik van katheters voor urinedrainage & zeer laag/laag & zwak \\
\hline & $\begin{array}{l}\text { het advies is om in neoblaas ureterstents en transure- } \\
\text { thrale katheter te gebruiken; optimale duur is onbekend }\end{array}$ & zeer laag/laag & \\
\hline $\begin{array}{l}\text { preventie postope- } \\
\text { ratieve ileus }\end{array}$ & $\begin{array}{l}\text { een multimodale aanpak waarin ten minste kauwgom en } \\
\text { magnesiumoxide kauwtabletten zitten }\end{array}$ & matig/matig & sterk \\
\hline $\begin{array}{l}\text { preventie postope- } \\
\text { ratieve nausea }\end{array}$ & $\begin{array}{l}\text { een multimodale aanpak waarin gebruikgemaakt kan } \\
\text { worden van goal-directed fluid therapy en vermijden van } \\
\text { opiaten }\end{array}$ & zeer laag/laag & sterk \\
\hline $\begin{array}{l}\text { postoperatieve } \\
\text { pijnstilling }\end{array}$ & epidurale pijnstilling & NA/hoog & sterk \\
\hline \multirow{3}{*}{$\begin{array}{l}\text { postoperatieve } \\
\text { mobilisatie }\end{array}$} & aanmoedigen van mobiliseren direct postoperatief & NA/laag & sterk \\
\hline & 2 uur uit bed op de dag van de operatie & NA/laag & \\
\hline & 6 uur uit bed op de eerste dag postoperatief & NA/laag & \\
\hline postoperatief dieet & oraal dieet starten 4 uur na de operatie & NA/matig & sterk \\
\hline audit & $\begin{array}{l}\text { patiënten moeten gevraagd worden naar hun mening over } \\
\text { opname }\end{array}$ & NA/laag & sterk \\
\hline
\end{tabular}


Hier staat een advertentie.

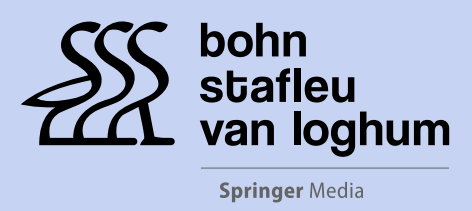

Houten 2017 
Hier staat een advertentie.

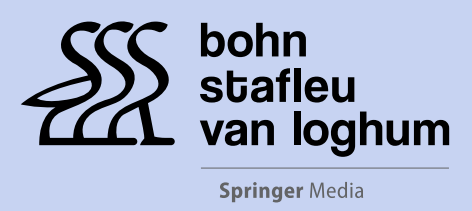

Houten 2017 
korter op de intensive care, maar de totale opnameduur was niet afgenomen. Het aantal complicaties was ook niet significant verschillend.

Collins et al. onderzochten in een retrospectieve studie het effect van ERAS op het postoperatieve beloop bij de RARC-IC [9]. Bij de groep met ERAS was de ASA-score significant hoger, maar de opnameduur korter en het aantal complicaties verschilde niet. In dit onderzoek speelde de leercurve geen rol, aangezien de operateurs (Wiklund en collega's) reeds veel ervaring hadden.

\section{Het ERAS-protocol bij colorectale chirurgie}

Preoperatief:

- Alle patiënten moeten preoperatieve counseling krijgen over de operatie en het verwachte beloop na de operatie. Goede uitleg vermindert de opnameduur [10]. Daarnaast wordt geadviseerd patiënten te motiveren om het eventuele roken te staken en zou een diëtist kunnen helpen om de voedingstoestand te optimaliseren [11].

- Er is geen verschil in morbiditeit en opnameduur bij patiënten die geen darmvoorbereiding krijgen ten opzichte van patiënten die dat wel krijgen [12]. Het geven van orale darmvoorbereiding lijkt dus niet nodig. Aangetoond is dat het geven van calorierijke drinkvoeding tot twee uur voor de operatie een positief effect heeft op het postoperatieve herstel [11]. Het wordt afgeraden om langwerkende benzodiazepines te gebruiken [1]

Peroperatief:

- Vanuit de colorectale chirurgie wordt geadviseerd om een thoracale epiduraalkatheter standaard deel te laten uitmaken van een ERAS-protocol. De katheter biedt voldoende pijnstilling en zou bijdragen aan een voorspoedig postoperatief herstel en minder complicaties op cardiopulmonaal gebied $[11,13]$. Alle onderzoeken naar de resultaten van de epiduraalkatheter bij de cystectomie zijn uitgevoerd bij open chirurgische ingrepen en onderzoek over het gebruik van de epiduraalkatheter bij minimaal invasieve technieken ontbreekt.

- Het gebruik van die minimaal invasieve technieken is nog niet standaard binnen het ERAS-protocol. Er is nog onvoldoende wetenschappelijk bewijs dat het gebruik van minimaal invasieve technieken ondersteunend werkt; de ERAS Society adviseert minimaal invasieve technieken enkel te gebruiken in centra waar hier veel ervaring mee is. Wel geeft het protocl aan dat men moet streven naar zo klein mogelijke incisies.

- Als antibioticaprofylaxe wordt een tweede- of derdegeneratie cefalosporine aangeraden; daarnaast wordt geadviseerd gebruik te maken van metronidazol [14]. Een eenmalige gift is voldoende, een tweede gift kan worden toegediend als de operatieduur de halfwaardetijd van de antibiotica overschrijdt. In de colorectale chirurgie wordt binnen het ERAS-protocol een intra-abdominale drain vaak achterwege gelaten. Voor urologische procedures wordt dit afgeraden, omdat bij de cystectomie, naast het gastro-intestinale systeem, ook de urinewegen worden geopend. Daarom wordt het advies vanuit de colorectale chirurgie om drains achterwege te laten, niet overgenomen voor de urologie.

- De anesthesie binnen het ERAS-protocol bestaat uit de al eerder genoemde thoracale epiduraalkatheter. Daarnaast wordt geadviseerd om hypothermie, hypoxie en hypovolemie te voorkomen [15]. Een belangrijk aspect is het peroperatieve vochtbeleid, met als doelstelling door middel van goal-directed fluid therapy te voorkomen dat de patiënt ondervuld raakt, maar ook niet te veel vocht krijgt. Hiermee wordt een sneller herstel bewerkstelligd, ontstaat er minder vaak een postoperatieve ileus en ervaren patiënten postoperatief minder klachten van nausea [16].

Postoperatief:

- De maaghevel kan direct postoperatief worden verwijderd. Het inlaten van de maaghevel heeft geen positief effect op morbiditeit, duur van de totale opname en tijd tot darmpassage postoperatief [17]. In de colorectale chirurgie wordt geadviseerd de transurethrale katheter de dag na de operatie te verwijderen. In verband met de aangelegde anastomosen in de urinewegen, wordt dit advies uiteraard niet overgenomen.

- Om een postoperatieve ileus te voorkomen, wordt naast de al eerder genoemde goal-directed fluid therapy, geadviseerd gebruik te maken van kauwgom. Met kauwgom komt de buik eerder op gang, kauwgom kauwen heeft echter geen effect op de morbiditeit of duur van de opname [18]. Het gebruik van magnesiumkauwtabletten wordt ook geadviseerd.

- Om postoperatief klachten van nausea te voorkomen, wordt geadviseerd gebruik te maken van de goal-directed fluid therapy en een minimum aan opiaten. Ook het plaatsen van stents in de ureteren vermindert de postoperatieve nausea.

- Mobiliseren dient zo snel als mogelijk is te worden opgestart, omdat immobilisatie de kans op pulmonale complicaties en trombo-embolieën vergroot. Het toepassen van antitromboseprofylaxe tot vier weken postoperatief maakt deel uit van het ERAS-protocol [19].

Het ERAS-protocol is gebaseerd op wetenschappelijk onderzoek bij colorectale chirurgie. Er is echter nog weinig solide bewijs voor het gebruik van het protocol bij de radicale cystectomie. Verder onderzoek moet meer duide- 
lijkheid geven over een op de urologie toegespitst protocol. Er zijn vooral vergelijkende studies nodig naar de preoperatieve (darm)voorbereiding, het gebruik van de epiduraalkatheter, het gebruik van minimaal invasieve technieken, postoperatieve mobilisatie en het dieet.

\section{Conclusie}

Toepassing van het ERAS-protocol voor colorectale chirurgie lijkt een positief effect te hebben op de opnameduur bij RARC. Deze kortere opnameduur gaat niet ten koste van meer complicaties. De kortere OK-tijd in onze serie heeft mogelijk ook invloed gehad op de opnameduur en het aantal complicaties. Daarnaast duurt het bij gebruik van het ERAS-protocol minder lang voordat de patiënt defecatie heeft en is er minder TPV nodig; een ileus kwam niet minder frequent voor.

Er is nog geen evidencebased ERAS-protocol bij RARC ontwikkeld en standaardisatie is duidelijk gewenst. Wij adviseren verder onderzoek naar de verschillende aspecten van het cystectomie-ERAS-protocol. Daarnaast moet uit onderzoek blijken of er verschillende protocollen moeten komen voor de open en minimaal invasieve technieken.

Open Access This article is distributed under the terms of the Creative Commons Attribution 4.0 International License (http:// creativecommons.org/licenses/by/4.0/), which permits unrestricted use, distribution, and reproduction in any medium, provided you give appropriate credit to the original author(s) and the source, provide a link to the Creative Commons license, and indicate if changes were made.

\section{Literatuur}

1. Varadhan KK, Neal KR, Dejong CH, Fearon KC, Ljungqvist O, Lobo DN. The enhanced recovery after surgery (ERAS) pathway for patients undergoing major elective open colorectal surgery: a meta-analysis of randomized controlled trials. Clin Nutr. 2010;29(4):434-40.

2. Shabsigh A, Korets R, Vora KC, Brooks CM, Cronin AM, Savage $\mathrm{C}$, et al. Defining early morbidity of radical cystectomy for patients with bladder cancer using a standardized reporting methodology. Eur Urol. 2009;55(1):164-74.

3. Clavien PA, Barkun J, Oliveira ML de, Vauthey JN, Dindo D, Schulick RD, et al. The Clavien-Dindo classification of surgical complications: five-year experience. Ann Surg. 2009;250(2):187-96.

4. Baack Kukreja JE, Messing EM, Shah JB. Are we doing 'better'? The discrepancy between perception and practice of enhanced recovery after cystectomy principles among urologic oncologists. Urol Oncol. 2016;34(3):120-1.

5. Cerantola Y, Valerio M, Persson B, Jichlinski P, Ljungqvist O, Hubner $\mathrm{M}$, et al. Guidelines for perioperative care after radical cystectomy for bladder cancer: Enhanced Recovery After Surgery (ERAS $((\mathrm{R})))$ society recommendations. Clin Nutr. 2013;32(6):879-87.
6. Abboudi H, Khan MS, Guru KA, Froghi S, Win G de, Poppel H van, et al. Learning curves for urological procedures: a systematic review. BJU Int. 2014;114(4):617-29.

7. Hayn MH, Hussain A, Mansour AM, Andrews PE, Carpentier P, Castle E, et al. The learning curve of robot-assisted radical cystectomy: results from the International Robotic Cystectomy Consortium. Eur Urol. 2010;58(2):197-202.

8. Karl A, Buchner A, Becker A, Staehler M, Seitz M, Khoder W, et al. A new concept for early recovery after surgery for patients undergoing radical cystectomy for bladder cancer: results of a prospective randomized study. J Urol. 2014;191(2):335-40.

9. Collins JW, Adding C, Hosseini A, Nyberg T, Pini G, Dey L, et al. Introducing an enhanced recovery programme to an established totally intracorporeal robot-assisted radical cystectomy service. Scand J Urol. 2016;50(1):39-46.

10. Smart NJ, White P, Allison AS, Ockrim JB, Kennedy RH, Francis NK. Deviation and failure of enhanced recovery after surgery following laparoscopic colorectal surgery: early prediction model. Colorectal Dis. 2012;14(10):e727-e734.

11. Nygren J, Thacker J, Carli F, Fearon KC, Norderval S, Lobo DN, et al. Guidelines for perioperative care in elective rectal/pelvic surgery: Enhanced Recovery After Surgery (ERAS((R))) Society recommendations. World J Surg. 2013;37(2):285-305.

12. Tabibi A, Simforoosh N, Basiri A, Ezzatnejad M, Abdi H, Farrokhi F. Bowel preparation versus no preparation before ileal urinary diversion. Urology. 2007;70(4):654-8.

13. Maffezzini M, Campodonico F, Capponi G, Manuputty E, Gerbi G. Fast-track surgery and technical nuances to reduce complications after radical cystectomy and intestinal urinary diversion with the modified Indiana pouch. Surg Oncol. 2012;21(3):191-5.

14. Grabe, Bjerklund-Johansen, Botto, Wullt, Cek, Naber, et al. Guidelines on urological infections. European Association of Urology; 2015.

15. Brandstrup B, Svendsen PE, Rasmussen M, Belhage B, Rodt SA, Hansen B, et al. Which goal for fluid therapy during colorectal surgery is followed by the best outcome: near-maximal stroke volume or zero fluid balance? Br J Anaesth. 2012;109(2):191-9.

16. Pillai P, McEleavy I, Gaughan M, Snowden C, Nesbitt I, Durkan $\mathrm{G}$, et al. A double-blind randomized controlled clinical trial to assess the effect of Doppler optimized intraoperative fluid management on outcome following radical cystectomy. J Urol. 2011;186(6):2201-6.

17. Nelson R, Edwards S, Tse B. Prophylactic nasogastric decompression after abdominal surgery. Cochrane Database Syst Rev. 2007;(3):CD004929. doi:10.1002/14651858.cd004929.pub3.

18. Choi H, Kang SH, Yoon DK, Kang SG, Ko HY, Moon DG, et al. Chewing gum has a stimulatory effect on bowel motility in patients after open or robotic radical cystectomy for bladder cancer: a prospective randomized comparative study. Urology. 2011;77(4):884-90.

19. Rasmussen MS. Prolonged thromboprophylaxis with low molecular weight heparin after major abdominal surgery. Curr Opin Pulm Med. 2007;13(5):389-92.

dr. Coen Holzhauer aios urologie

dr. Philip C. Weijerman uroloog

dr. Geert A.H.J. Smits uroloog

drs. Carl J. Wijburg uroloog 